\title{
Two New Soleid Flatfishes (Pleuronectiformes: Soleidae: Soleichthys) from Australian Waters, With a Re-description of Soleichthys microcephalus (Günther)
}

\author{
Thomas A. Munroe ${ }^{1 *}$ And Sean B. MenKE ${ }^{2}$ \\ ${ }^{1}$ National Systematics Laboratory, NMFS/NOAA, Smithsonian Institution, \\ PO Box 37012, NHB, WC 57, MRC-153, Washington, DC 20013-7012, United States of America \\ Munroe.Thomas@nmnh.si.edu \\ ${ }^{2}$ Division of Biological Sciences, MC-0116, University of California, \\ San Diego, 9500 Gilman Drive, Room M2B-4266, La Jolla, California 92093-0116, United States of America \\ smenke@biomail.ucsd.edu
}

\begin{abstract}
Soleichthys microcephalus (Günther, 1862) occurring in warm temperate waters off New South Wales, Australia, is re-described based on examination of a syntype and additional non-type material. This species differs from congeners in its combination of: low meristic features (43-45 vertebrae, 71-84 dorsal-fin rays, 61-71 anal-fin rays, and 81-89 lateral-line scales); in having two elongated ocular-side pectoral-fin rays of nearly equal length; with small scales present on the ocular-side pectoralfin base and proximal halves of elongated pectoral-fin rays; in its ocular-side pigmentation consisting of a series of 8-10 mostly complete, bold, wide, dark-brown or blackish crossbands of nearly uniform width throughout their lengths and noticeably wider than the alternating lighter-coloured crossbands; and with two, conspicuous, mid-lateral white spots arranged in horizontal series. Two new species phenotypically most similar to, and with meristic features that largely overlap those of $S$. microcephalus, are described from specimens collected in tropical waters of northern Australia. Soleichthys serpenpellis n.sp., known from the Gulf of Carpentaria and Delambre Island, Dampier Archipelago, northwestern Australia, is easily distinguished from S. microcephalus and other congeners by its ocular-side head and body pigmentation featuring incomplete, diamond-shaped crossbands broadest in their mid-sections, fewer (about 6) ocular-side body crossbands, and with small, brown spots scattered in the interspaces between the crossbands. Soleichthys oculofasciatus $\mathrm{n}$.sp. occurs off northeast Australia and is distinguished from congeners in its combination of a first elongate ocular-side pectoral-fin ray longer than the second, in lacking scales on the ocular-side pectoral-fin base and elongate pectoral-fin rays, in having a longitudinal series of crossbands (usually 11) on the ocular-side head and body, and with four conspicuous white spots on the body, two of which are arranged in a vertical series at mid-body. The new species differs further from both $S$. microcephalus and S. serpenpellis in having a longer and narrower head and a longer caudal fin.
\end{abstract}

Munroe, Thomas A., \& Sean B. Menke, 2004. Two new soleid flatfishes (Pleuronectiformes: Soleidae: Soleichthys) from Australian waters, with a re-description of Soleichthys microcephalus (Günther). Records of the Australian Museum 56(2): 247-258. 